\author{
И.Ж. Шубина, Е.М. Трещалина, С.А. Кузнецов, Г.Б. Смирнова, Ю.А. Борисова, \\ С.М. Ситдикова, М.В. Киселевский, З.С. Шпрах \\ ФГБУ «НМИЦ онкологии им. Н.Н. Блохина» Минздрава России; Россия, 115478 Москва, Каширское ш., 24
}

Контакты: Ирина Жановна Шубина irinashubina@mail.ru

Введение. Эффективность фитоантиэстрогена секоизоларицирезинола (СЕКО) из группы лигнанов аналогична эффективности селективного модулятора экстрогенных рецепторов тамоксифену (ТАМ) на эстрогенпозитивных моделях рака молочной железы (РМЖ) мышей и человека іп vіvо. Тамоксифен в силу антагонистических и агонистических свойств одновременно с эффективной профилактикой метастазирования РМЖувеличивает риск развития аденокарииномы матки. Влияние СЕКО на пролиферативную активность циркулирующих опухолевых клеток, а также их способность к прогрессии (образование скрытых метастазов) не изучена.

Цель исследования - оценка риска диссеминации опухолевых клеток у мышей с перевиваемой аденокарииномой молочной железы под действием СЕКО в сравнении с ТАМ.

Материалы и методы. Исследование проводили на мышах линии $B D F_{1}\left[C_{57} B l_{6 j} \times D B A_{2}\right]$ с подкожно привитой карциномой молочной железы Са755. Для выявления диссеминированных опухолевых клеток использовали эпителиальный маркер внутриклеточный цитокератин СК19. Оиенку содержания СК19-положсттельных клеток в циркуляции и костном мозге животных проводили методом проточной цитометрии и иммунофлуоресцентной микроскопии через 24 ч после 10-дневного введения СЕКО (в эффективной разовой дозе 250 мг/кг) или ТАМ (в разовой дозе 50 мг/кг).

Результаты. В группах мышей, получавших СЕКО и ТАМ, величины среднего геометрического интенсивности флуоресцениии

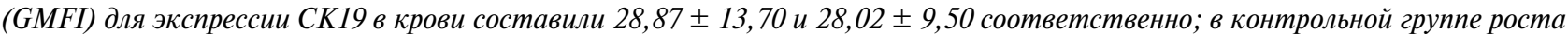
опухоли (КРО) без лечения - 31,94 \pm 5,02. Показатель GMFI экспрессии СК19 в костном мозге в группах СЕКО, ТАМ и КРО составил 30,14 \pm 2,33; 39,07 $\pm 2,30$ и 32,48 $\pm 3,75$ соответственно.

Заключение. В результате установлено, что у мышей с аденокарциномой молочной железы Са 755 , чувствительной к СЕКО или ТАМ, показатели экспрессии СК19 в клетках периферической крови имеют близкие значения и недостоверно отличаются от такового в контрольной группе животных. В костном мозге мышей-опухоленосителей показатель GMFI экспрессии СК19 в группе СЕКО был достоверно ниже по сравнению с этим показателем в группе ТАМ (p=0,0003). Данные, полученные на мышиной модели, свидетельствуют в пользу низкого риска потенцирования диссеминации клеток аденокарииномы молочной железы при применении фитоантиэстрогена СЕКО по терапевтической схеме.

Ключевые слова: фитоантиэстроген, секоизоларицирезинол, СК19, опухолевая диссеминация

DOI: $10.17650 / 1726-9784-2018-17-3-43-49$

\title{
EXPRESSION OF EPITHELIAL MARKER CK19 IN MICE WITH MAMMARY ADENOCARCINOMA AFTER EXPOSURE TO FITO-ANTI-ESTROGEN SECOISOLARICIRESINOL
}

\author{
I.Zh. Shubina, E.M. Treshalina, S.A. Kuznetsov, G.B. Smirnova, Yu.A. Borisova, S.M. Sitdikova, M.V. Kiselevsky, Z.S. Shprakh \\ N.N. Blokhin National Medical Research Center of Oncology, Ministry of Health of Russia; \\ 24 Kashirskoe Shosse, Moscow 115478, Russia
}

Introduction. Phyto-anti-estrogen secoisolariciresinol (SECO) has similar effectiveness to that of Tamoxifen (TAM), a member of selection estrogen receptor modulators, in estrogen-positive models of murine mammary adenocarcinoma and human breast cancer in vivo. Due to its antagonistic and agonistic functions Tamoxifen may enhance risk of development of uterine adenocarcinoma while providing effective prophylactics of breast cancer metastases. SECO effect on proliferative activity of circulating or disseminating tumor cells (occult metastases) is still unclear. We used epithelial cell marker - intracellular cytokeratin 19 (CK19) to study SECO function in terms of possible metastatic process, since prognostic significance of CK19 is well established for identifying occult metastases and breast cancer dissemination.

Objective. To evaluate risk of tumor cell dissemination in mice with transplanted mammary adenocarcinoma after exposure to SECO and TAM. 
Materials and methods. Mice $B D F_{1}\left[C_{57} B l_{6 j} \times D B A_{2}\right]$ bearing Ca 755 of the $3^{\text {rd }}$ passage were used for the experiments. CK19 expression was evaluated 24 hours after 10-day course of SECO in the effective single doses of $250 \mathrm{mg} / \mathrm{kg}$ or TAM $50 \mathrm{mg} / \mathrm{kg}$. Flow cytometry, immunofluorescence with light and luminescence microscopy were performed to evaluate CK19 expression.

Results. Parameter GMFI $\pm S D$ (geometric mean fluorescence intensity \pm SD) for CK19 expression in SECO and TAM groups in blood accounted for $28.87 \pm 13.70$ and $28.02 \pm 9.50$ and in control tumor growth (CTG) group GMFI $\pm S D$ was $31.94 \pm 5.02 ;$ while in bone marrow it was $30.14 \pm 2.33,39.07 \pm 2.30$ and $32.48 \pm 3.75$, respectively.

Conclusion. The results of the study showed similar expression of epithelial intracellular marker CK19 in blood in the studied groups of mice bearing mammary adenocarcinoma Ca 755 sensitive to SECO and TAM exposure. GMFI for CK19 expression in bone marrow was lower in SECO group than in TAM ( $p=0.0003)$. The data obtained in the murine model demonstrated no enhanced risk of tumor cell dissemination while performing treatment by phyto-anti-estrogen SECO in therapeutic regimen.

Key words: phyto-anti-estrogen, secoisolariciresinol, CK19, tumor dissemination

\section{Введение}

Новый пероральный фитоантиэстроген из группы лигнанов (полифенольные соединения) секоизоларицирезинол (СЕКО) со свойствами селективных модуляторов эстрогенных рецепторов при доклиническом изучении на эстроген-позитивных опухолевых моделях рака молочной железы (РМЖ) животных и человека показал эффективность, аналогичную эффективности тамоксифена (ТАМ) [1-9]. При этом известно, что ТАМ в силу антагонистических и агонистических свойств наряду с эффективной профилактикой метастазирования РМЖ стимулирует пролиферацию эндометрия и увеличивает риск развития аденокарциномы матки $[10,11]$. Для изучения влияния СЕКО на содержание диссеминированных опухолевых клеток в периферическом кровотоке и костном мозге использован маркер эпителиальных клеток - внутриклеточный цитокератин СК19, для которого хорошо подтверждена прогностическая значимость в отношении выявления скрытого метастазирования при РМЖ.

Экспрессия СК19 в диссеминированных опухолевых клетках визуализируется практически с одинаковой чувствительностью различными методами: при помощи полимеразной цепной реакции, иммунофлуоресценции или методом проточной цитометрии. Получение доказательных данных, как правило, достигается сочетанием этих методов [12-17]. Показана перспективность детекции циркулирующих опухолевых клеток с иммунофенотипом CD45$/ \mathrm{CK} 8 / 18^{+} / \mathrm{CK} 19^{+}$при эпителиальных опухолях различных локализаций, демонстрирующая высокую частоту выявления опухолевых клеток у больных генерализованными формами злокачественных новообразований $[18,19]$.

В данной работе для определения in vivo влияния фитоантиэстрогена CEKO на содержание CK19+ клеток использованы 2 из 3 перечисленных методов. В качестве препарата сравнения использован ТАМ в оптимальной схеме применения.

Цель и задачи исследования - оценка риска диссеминации опухолевых клеток в крови и костном мозге мышей с перевиваемой аденокарциномой молочной железы под действием СЕКО или ТАМ при помощи маркера СК19.

\section{Материалы u методы}

\section{Лабораторные животные}

В опытах использованы мыши, полученные из разведения ФГБУ «НМИЦ онкологии им. Н.Н. Блохина» Минздрава России. Мышей содержали в виварии отдела экспериментальных животных ФГБУ «НМИЦ онкологии им. Н.Н. Блохина» Минздрава России. В эксперименте использовали 30 мышей-самок гибридов $\mathrm{BDF}_{1}\left[\mathrm{C}_{57} \mathrm{Bl}_{6 \mathrm{j}} \times \mathrm{DBA}_{2}\right](2$ здоровые особи - для группы интактного контроля, 28 особей - для трансплантации опухоли и/или лечения). В качестве доноров опухолевого материала Са755 использованы 4 мыши-самки линии $\mathrm{C}_{57} \mathrm{Bl}_{6}$ Масса тела всех мышей - 19-20 г.

Группы мышей:

- группа контроля роста опухоли (KРО, $n=5)$ : мышам трансплантировали опухоль и давали перорально $1 \%$-ный раствор крахмального клейстера в сроки и режиме, аналогичном применению агентов;

- группа CЕКО $(n=17)$ : мышам трансплантировали опухоль и проводили лечение субстанцией CEKO;

- группа ТАМ $(n=17)$ : мышам трансплантировали опухоль и проводили лечение аптечным препаратом ТАM.

\section{Опухолевая модель}

Использован штамм гормонозависимой аденокарциномы молочной железы мышей Сa755 из криохранилища банка ФГБУ «НМИЦ онкологии им. Н.Н. Блохина» Минздрава России, показавший ранее чувствительность к СЕКО или ТАМ [2-4]. В опытах использовали 3-ю генерацию опухоли in vivo. Инокулят готовили ex tempore в питательной среде 199 и трансплантировали мышам под кожу бока по 40 мг опухолевой ткани в 0,4 мл $10 \%$ взвеси. Все исследования на мышах с опухолями проведены 
и проанализированы в соответствии с действующими в Российской Федерации методическими рекомендациями [20].

\section{Секоизоларицеризинол}

Для опытов использован СЕКО производства ЗАО «Биохиммак СТ» (Россия). Мыши группы СЕКО получали субстанцию СЕКО перорально ежедневно в течение 10 сут (3-12) в разовой дозе 250 мг/кг. Взвесь СЕКО в $1 \%$-ном растворе крахмального клейстера вводили в желудок каждой мыши с помощью металлического зонда.

\section{Тамоксифен}

Клинический селективный модулятор рецепторов эстрогенов аптечный ТАМ в таблетках по 10 мг («Эбеве», Швейцария) использован в качестве референсного препарата для СЕКО как функциональный аналог. Таблетку ТАМ предварительно растирали в фарфоровой ступке, а затем растворяли в питьевой воде. Мышам вводили ТАМ в разовой дозе 50 мг/кг в режиме ежедневного перорального введения в желудок с помощью металлического зонда в течение 10 сут (3-12).

\section{Материал для иммунологического \\ и иммунохимического исследований}

На 1-е сутки после лечения СЕКО или ТАМ всех мышей умерщвляли с помощью декапитации. Образцы периферической крови (ПК) по 0,5 мл от каждой мыши собирали в гепаринизированные пробирки. Образцы костного мозга (KM) забирали с помощью инъекционного шприца из 2 бедренных костей от каждой мыши, после чего помешали в пробирки с физиологическим раствором и подвергали соответствующему исследованию.

\section{Завершение экспериментов}

Для взятия материала и после завершения эксперимента мышей умерщвляли передозировкой эфирного наркоза. Трупы кремировали в специализированном подразделении ФГБУ «НМИЦ онкологии им. Н.Н. Блохина» Минздрава России. Манипуляции, умерщвление и кремация мышей выполнены с учетом международных рекомендаций по проведению медико-биологических исследований с использованием животных, изложенных в Европейской конвенции о защите позвоночных животных, используемых для экспериментальных и других научных целей, а также требований Хельсинкской декларации и Всемирной медицинской ассоциации [21, 22].

\section{Проточная цитометрия}

Для визуализации маркера использованы моноклональные антитела (МКА) к СК19 (А53-В/А2.26;
Cell Marque, США) и MKA к IG1, меченные FITC (BD Biosciences, США). Образцы КМ и ПК от мышей с опухолью обрабатывали стандартно с применением пермеабилизации (изменение проницаемости мембраны клетки). Полученный материал КМ отмывали центрифугированием при $300 \mathrm{~g}$ в течение 3 мин в 1 мл раствора Хэнкса без красителя («ПанЭко», Россия), осадок ресуспендировали и инкубировали в 1 мл холодного свежеприготовленного фиксирующего/пермеабилизирующего буфера (Permeabilization Kit, BD Biosciences, CША) в темноте при $4{ }^{\circ} \mathrm{C}$ в течение 30 мин. Затем все клетки дважды отмывали в 1 мл холодного буфера центрифугированием при $300 \mathrm{~g}$ в течение 3 мин при $4{ }^{\circ} \mathrm{C}$. После блокировки Fc-peцепторов соответствующим реагентом в объеме 20 мкл к клеткам добавляли 10 мкл МКА СК19 (меченных FITC). Затем суспензию клеток инкубировали при комнатной температуре в течение 30 мин. После отмывки центрифугированием при $300 \mathrm{~g}$ в течение 3 мин при $4{ }^{\circ} \mathrm{C}$ осажденную популяцию клеток использовали для исследования на проточном цитофлуориметре.

Окрашивание образцов ПК МКА СК19 проводили таким же способом, при этом на последнем этапе добавляли лизирующий буфер OptiLyse C (BD Biosciences, CША) для лизиса эритроцитов. Полученные окрашенные пробы использовали для последующего измерения на проточном цитофлуориметре FACS CANTO II (Becton Dickinson, США). Данные анализировали с помощью программы WinMDI 2.8 по показателю GMFI (Geometrical Mean Fluorescence Intensity) - параметру, отражающему среднее геометрическое величины интенсивности флуоресценции клеток при использовании логарифмической шкалы подсчета с оценкой соответствующей величины стандартного отклонения $( \pm \mathrm{SD})$.

\section{Флуоресцентная микроскопия}

Визуализацию экспрессии внутриклеточного маркера СК19 проводили с использованием флуоресцирующих FITC-меченных MKA к CK19. Прижизненную флуоресцентную, а также световую микроскопию и фотографирование клеток выполняли с использованием люминесцентного микроскопа, соответствующих светофильтров, а также цифровой системы регистрации и анализа изображения (Zeiss Axio Vision, Германия).

\section{Результаты}

Результаты оценки характера распределения и интенсивность флуоресценции маркера СК19 по показателю GMFI в ПК и КМ мышей с подкожно привитой аденокарциномой Са755, получавших лечение СЕКО или ТАМ, представлены в таблице. 
Экспрессия СК19 в клетках периферической крови и костного мозга мышей с аденокарциномой Са 755 после лечения секоизоларицирезинолом или тамоксифеном

\begin{tabular}{|l|l|l|}
\hline \multicolumn{1}{|c|}{ Группа } & Экспрессия CK19 (GMFI \pm SD) \\
\hline \multicolumn{1}{|c|}{ костный мозг } & $\begin{array}{c}\text { периферическая } \\
\text { кровь }\end{array}$ \\
\hline Контроль роста опухоли & $32,48 \pm 3,75$ & $31,94 \pm 5,02$ \\
\hline Секоизоларицирезинол & $30,14 \pm 2,33$ & $28,87 \pm 13,70$ \\
\hline Тамоксифен & $39,07 \pm 2,30 *$ & $28,02 \pm 9,50$ \\
\hline
\end{tabular}

Примечание. GMFI - среднее геометрическое интенсивности флуоресценции клеток при использовании логарифмической шкалы подсчета; $S D$ - стандартное отклонение, ${ }^{*} p<0,05$.

Как видно из представленных данных, показатель GMFI экспрессии CK19 в клетках KM в группе мышей, получавших инъекции СЕКО, оказался близким к показателю в контрольной группе животных (отличия статистически недостоверны) и достоверно ниже, чем у животных, получавших лечение TAM $(p=0,0003)$. Показатель GMFI экспрессии CK19 в костном мозге мышей после лечения ТАМ достоверно превышал таковой в контрольной группе животных $(p=0,01)$.

По результатам анализа образцов ПК животных-опухоленосителей в группах мышей, получавших лечение СЕКО или ТАМ, показатели GMFI для экспрессии СК19 были сходными, а величины GMFI в этих группах были ниже, чем в контрольной группе животных (различия статистически недостоверны).

$a$

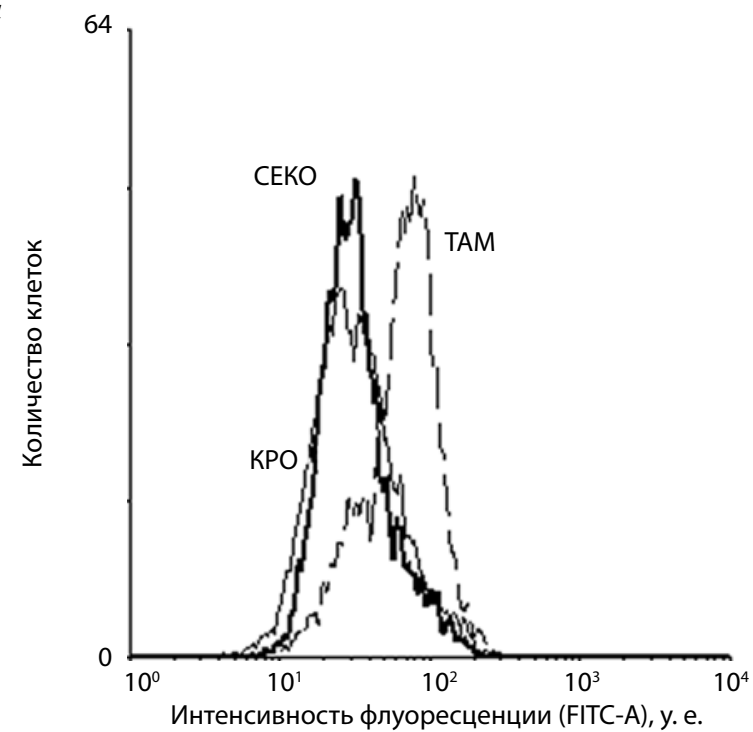

Приведенные на рис. 1 гистограммы демонстрируют уровень интенсивности флуоресценции и характер распределения окрашенных МКА к СК19 клеток в образцах КМ и ПК мышей-опухоленосителей в контрольной группе и в группах, получавших лечение СЕКО или ТАМ.

Иммунофлуоресцентный анализ при микроскопическом исследовании позволил выявить в КМ единичные CK19+ клетки у мышей с привитой опухолью во всех группах (рис. 2).

\section{Заключение}

В результате проведенного исследования установлено, что в ПК и КМ мышей с гормонозависимой аденокарциномой молочной железы Са755 выявляются клетки, экспрессирующие эпителиальный маркер CK19. Этот феномен свидетельствует о том, что известная в экспериментальной онкологии как неметастазирующая аденокарцинома молочной железы $\mathrm{Ca} 755$ у мышей-самок $\mathrm{BDF}_{1}$ при подкожной перевивке в течение 14 дней роста диссеминирует в КМ, т. е. дает скрытые микрометастазы. Оценка опухолевой диссеминации по числу и интенсивности флуоресценции СK $19^{+}$клеток после проведения у животных-опухоленосителей лечения антиэстрогенами выявила более низкие показатели экспрессии СК19 в КМ мышей, получавших СЕКО, по сравнению с группой ТАМ.

Данные, полученные на мышиной модели, свидетельствуют о том, что терапия СЕКО в эффективных дозах не сопровождается усилением диссеминации клеток мышиной гормонозависимой аденокарциномы молочной железы Са755 в КМ.

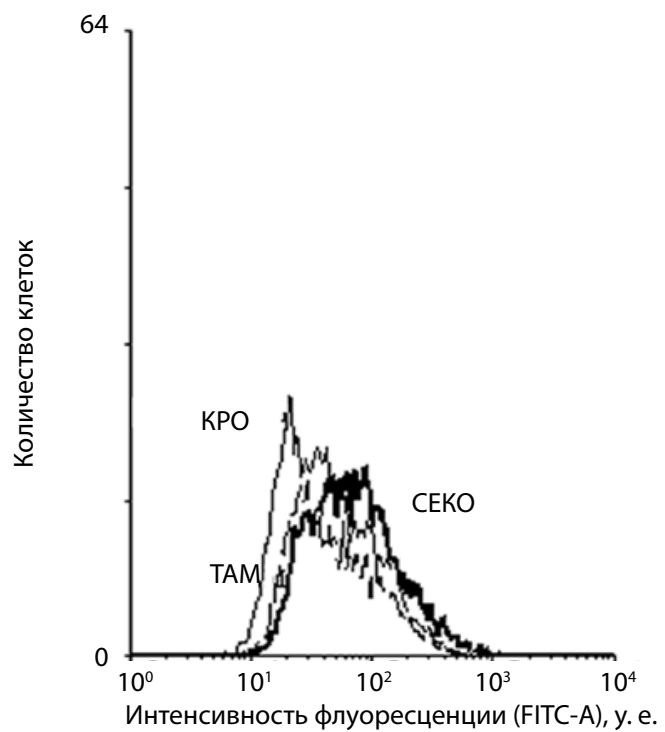

Рис. 1. Гистограммы распределения СК19+ клеток в КМ и ПКмышей с аденокарииномой Са755, получавших СЕКО или ТАМ в терапевтических дозах: $a$ - костный мозг; б - периферическая кровь; контроль флуоресценции МКА (FITC) 

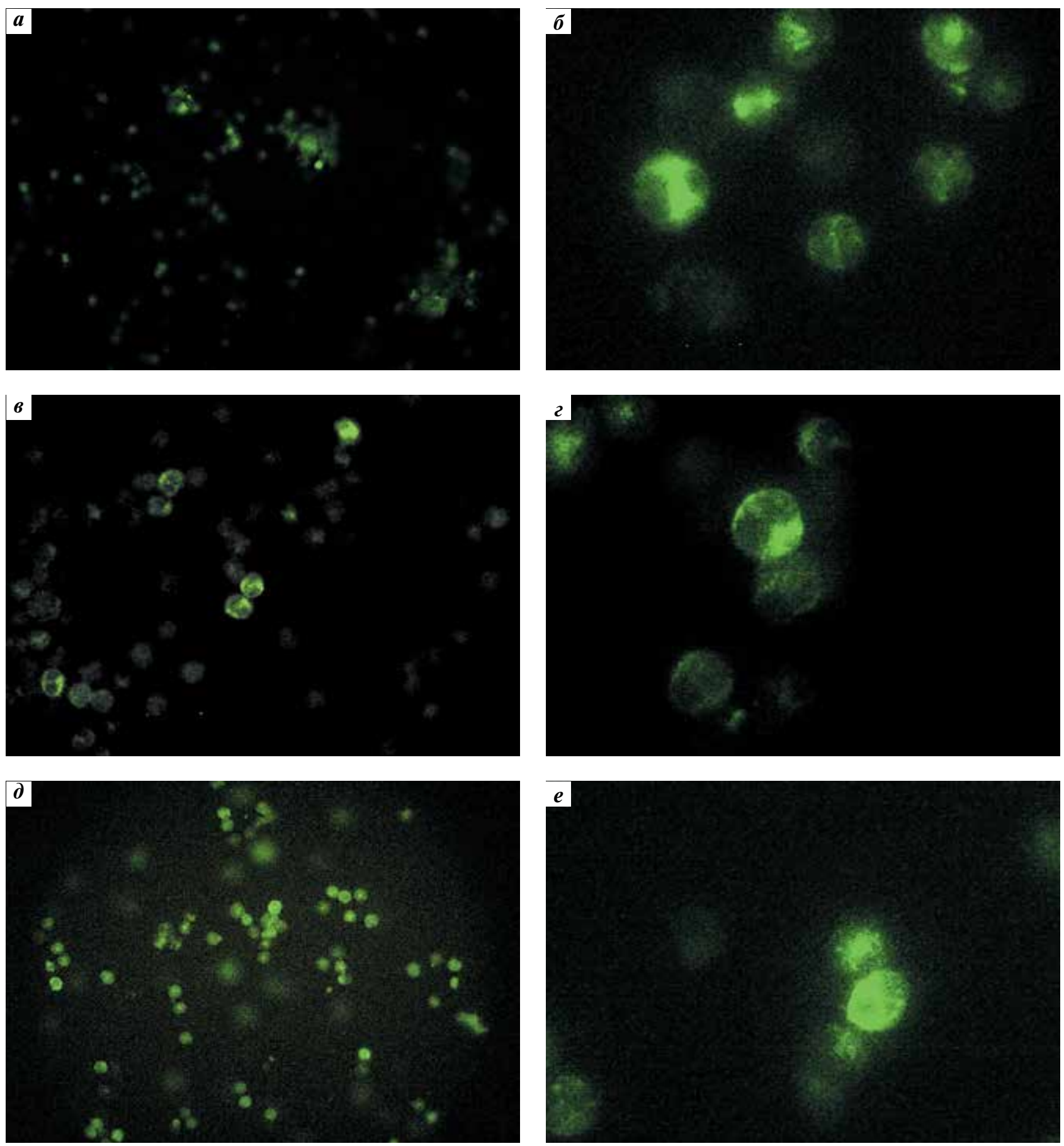

Рис. 2. Иммунофлуоресценция СК19+ клеток в костном мозге мышей с аденокарциномой Са 755 в контрольной группе (КРО) и в группах животных, получавших лечение секоизоларицирезинолом (СЕКО) или тамоксифеном (ТАМ) в терапевтических дозах: $a-K P O, \times 40 ; 6-K P O$, $\times 100 ;$ в - СЕКО 250 мг/кг десятикратно, × 140; г - СЕКО 250 мг/кг десятикратно, × 100; д - ТАМ 50 мг/кг десятикратно, × 40; e-TAM 50 мг/кг десятикратно, × 1100 


\section{J И T E P A T}

1. Milder I.E., Arts I.C., van de Putte B. Lignan contents of Dutch plant foods: a database including lariciresinol, pinoresinol, secoisolariciresinol and matairesinol. Br. J Nutr 2005;93(3):393-402. DOI: $10.1079 / \mathrm{BJN} 20051371$

2. Нифантьев Н.Э., Яшунский Д.В., Меньшов В.М. Патент РФ 2359666, 2009. Способ выделения секоизоларицирезинола и дигидрокверцетина из древесины. [Nifantjev N.E., Yashunsky D.V., Menshov V.M. Patent RU 2359666, 2009. Method of isolation of secoisolariciresinol and dihydroquercetin from wood (In Russ.)].

3. Седакова Л. А, Смирнова Г.Б., Борисова Ю.А., Трещалина Е.М. Результаты скрининга нового фитоантиэстрогена секоизоларицирезинола на гормонозависимой опухолевой модели in vivo. Российский биотерапевтический журнал 2013;12(2):73. [Sedakova L.A., Smirnova G.B., Borisova Yu.A., Treschalina E.M. Results of screening of the new phyto-antiestrogen secoisolariciresinol in a hormone-dependent tumor model in vivo. Rossiysky Bioterapevtichesky Zhurnal = Russian Journal of Biotherapy 2013;12(2):73 (In Russ.)].

4. Седакова Л.А., Борисова Ю.А., Смирнова Г.Б., Трещалина Е.М. Сравнительная эффективность секоизоларицирезинола и тамоксифена, в том числе в комбинации с аримидексом. Российский биотерапевтический журнал 2013;12(2):73.

[Sedakova L.A., Borisova Yu.A., Smirnova G.B., Treschalina E.M. Comparative effectiveness of secoisolariciresinol and tamoxifen including that in combination with arimidex. Rossiysky Bioterapevtichesky Zhurnal $=$ Russian Journal of Biotherapy 2013;12(2):73 (In Russ.)].

5. Седакова Л.А., Борисова Ю.А., Смирнова Г.Б., Трешалина Е.М. Действие нового антиэстрогенного препарата секоизоларицирезинола на рост запушенной эстрогензависимой опухоли и метастазирование меланомы B16/F10. Российский биотерапевтический журнал 2013;12(3):74. [Sedakova L.A., Borisova Yu.A., Smirnova G.B., Treschalina E.M. Effect of the new anti-estrogenic drug secoisolariciresinol on the growth of estrogen-dependent advanced tumor and metastases of melanoma B16/F10. Rossiysky Bioterapevtichesky Zhurnal = Russian Journal of Biotherapy 2013;12(3):74 (In Russ.)].
6. Борисова Ю.А., Смирнова Г.Б., Райхлин Н.Т., Трещалина Е.М. Результаты скрининга фитоантиэстрогена секоизоларицирезинола на эстрогензависимой аденокарциноме молочной железы Са755. Вестник РОНЦ им. Н.Н. Блохина РАМН, 2014;25(1-2):26-30. [Borisova Yu.A., Smirnova G.B., Reichlin N.T.,

Treschalina E.M. Results of screening of phytoantiostrogen secoizolariciresinol on estrogen-dependent adenocarcinoma of the mammary gland Ca755. Vestnik RONC im. N.N. Blokhina = Journal of N.N. Blokhin Russian Cancer Research Center 2014;25(1-2):26-30 (In Russ.)].

7. Борисова Ю.А., Смирнова Г.Б., Андронова Н.В. и др. Результаты доклинического изучения секоизоларицирезинола на опухолевых моделях in vivo. Вестник РОНЦ им. Н.Н. Блохина 2014;25(3-4):43-6.

[Borisova Yu.A., Smirnova G.B., Andronova N.V. et al. Results of preclinical study of secoisolariciresinol on tumor models in vivo. Vestnik RONC im. N.N. Blokhina $=$ Journal of N.N. Blokhin Russian Cancer Research Center 2014;25(3-4):43-6 (In Russ.)]

8. Борисова Ю.А., Смирнова Г.Б., Андронова Н.В. и др. Результаты доклинического изучения секоизоларицирезинола на подкожных ксенографтах рака молочной железы человека. Вестник РОНЦ им. Н.Н. Блохина 2015;26(1):47-51. [Borisova Yu.A., Smirnova G.B., Andronova N.V. et al. Results of preclinical study of secoisolariciresinol on subcutaneous xenografts of human breast cancer. Vestnik RONC im. N.N. Blokhina $=$ Journal of N.N. Blokhin Russian Cancer Research Center 2015;26(1):47-51 (In Russ.)].

9. Борисова Ю.А., Смирнова Г.Б., Шубина И.Ж. и др. Фитоэстрогены потенциальные селективные модификаторы биологически активных реакций при раке молочной железы. Российский онкологический журнал 2016;21(4):212-9. [Borisova Yu.A., Smirnova G.B., Shubina I.Zh. et al. Phytoestrogens are potential selective modifiers of biologically active reactions in breast cancer. Rossiysky Onkologichesky Zhurnal = Russian Journal of Oncology 2016;21(4):212-9 (In Russ.)].

10. Neis K.J., Brandner P., Schlenker M. Tamoxifen-induced hyperplasia of the endometrium. Contrib Gynecol Obstet 2000;20:60-8. PMID: 11791286.

11. Дмитриева Е.В., Пустотина О.А., Костин И.Н. Состояние эндометрия у женщин, получающих адъювантную терапию тамоксифеном после хирургического лечения рака молочной железы. Вестник РУДН 2013;5:219-24. [Dmitrieva E.V., Pustotina O.A., Kostin I.N. Status of endometrium in women receiving adjuvant therapy with tamoxifen after surgical treatment of breast cancer. Vestnik RUDN = Journal of Peoples' Friendship University of Russia 2013;5:219-24 (In Russ.)].

12. Xenidis N., Mavroudis D., Kalmanti L. et al. Effect of adjuvant Tamoxifen and Letrozol on the fate of peripheral blood CK-19 mRNA+ cells in patients with early breast cancer. Ann Oncol 2007; 18:1623-31. DOI: $10.1093 /$ annonc/mdm208.

13. Saloustros E., Perraki M., Apostolaki S. et al. Cytokeratin-19 mRNA-positive circulating tumor cells during follow-up of patients with operable breast cancer: prognostic relevance for late relapse. Breast Cancer Research 2011;13(R60): 2-11. DOI. ORG/10.1186/BCR2897.

14. Braun S., Pantel K., Muller P. et al. Cytokeratin-positive cells in the bone marrow and survival of patients with stage I, II, or III breast cancer. N Engl J Med 2000;342:525-33. DOI: 10.1056/NEJM200002243420801. PMID: 10684910.

15. Stathopoulou A., Onikolis I., Mavroudis D. et al. Molecular detection of cytokeratin-19-positive cells in the peripheral blood of patients with operable breast cancer: evaluation of their prognostic significance. J Clin Oncol 2002;20:3404-12. DOI: $10.1200 / J C O .2002 .08 .135$ PMID: 12177100

16. Wang L., Wang Y., Liu Y. et al. Flow cytometric analysis of CK19 expression in the peripheral blood of breast carcinoma patients: relevance for circulating tumor cell detection. J Exp Clin Cancer Res 2009;28(1):57. DOI: 10.1186/1756-9966-28-57.

17. Шубина И.Ж., Борисова Ю.А., Смирнова Г.Б. и др. Диссеминация клеток аденокарциономы молочной железы Са755 в костный мозг мышей на фоне селективных модификаторов эстрогеновых рецепторов (СМЭР). Российский биотерапевтический журнал 2015;13(1):146-7. [Shubina I.Zh., Borisova Yu.A., Smirnova G.B. et al. Dissemination of adenocarcinoma cells of the mammary 
gland Ca755 into the bone marrow of mice against the background of selective modifiers of estrogen receptors(SMER). Rossiysky Bioterapevtichesky Zhurnal = Russian Journal of Biotherapy 2015;13(1):146-7. (In Russ.)].

18. Sparano J., O’Neill A., Alpaugh K. et al. Circulating tumor cells five years after diagnosis are prognostic for late recurrence in operable stage II-III breast cancer. 2018; San Antonio Breast Cancer Symposium. Abstract GS6-03.

19. Кит О.И., Новикова И.А., Селютина О.Н. и др. Исследование уровня ЦОК при эпителиальных опухолях различных локализаций. Международный журнал прикладных и фундаментальных исследований 2015;12(5):817-20. [Kit O.I., Novikova I.A., Selutina O.N. et al. Study of the CSC level in epithelial tumors of various localizations. Mezhdunarodny Zhurnal Prikladnykh i Fundamentalnykh Issledovaniy $=$ International Journal of Applied and Fundamental Research. 2015;12(5):817-20 (In Russ.)].

20. Трешалина Е.М., Жукова О.С., Герасимова Г.К. и др. Методические рекомендации по доклиническому изучению противоопухолевой активности лекарственных средств. В кн. Руководство по проведению доклинических исследований лекарственных средств. Часть первая.

М.: Гриф и К, 2012. С. 642-657.

[Treschalina E.M., Zhukova O.S.,

Gerasimova G.K. et al. Guidelines for pre-clinical study of antitumor activity of drugs. In: Guidelines for pre-clinical trials of drugs. Part one. M.: Grif i K, 2012. P. 642-657 (In Russ.)].

21. Европейская конвенция по защите позвоночных животных, используе- мых для экспериментальных и других научных целей. ЕЭС. Страсбург, 1985. Анималогия 1993;1:29. [European Convention for the protection of vertebrate animals used for experimental and other scientific purposes, EEC, Strasbourg, 1985; Animalogiya $=$ Animalogy 1993;1:29 (In Russ.)].

22. Большаков О.П., Незнанов Н.Г., Бабаханян Р.В. Дидактические и этические аспекты проведения исследований на биомоделях и на лабораторных животных. Качественная клиническая практика 2002;1:54-9. [Bolshakov O.P., Neznanov N.G., Babakhanyan R.V. Didactic and ethical aspects of research on biomodels and laboratory animals. Kachestvennaya Klinicheskaya Praktika $=$ Quality clinical practice. 2002;1:54-9 (In Russ.)].

ORCID авторов / ORCID of authors

И.Ж. Шубина / I.Zh. Shubina: http://orcid.org/0000-0002-9374-3158

С.M. Ситдикова / S.M. Sitdikova: http://orcid.org/0000-0002-2840-1186

М.В. Киселевский / M.V. Kiselevsky: http://orcid.org/0000-0002-0132-167X

Конфликт интересов. Авторы заявляют об отсутствии конфликта интересов. Conflict of interest. The authors declare no conflict of interest. 